\title{
Study of the effect of cabbage juice (Brássica olerácea), as a source of inhibition of microorganisms of the genus Bacillus in the preparation of whole grain wheat bread
}

\author{
L.Zh. Alashbayeva1, D.A. Shansharova ${ }^{2}$, H. Luděk ${ }^{3}$, M.D. Kenzhekhojayev ${ }^{4}$, N.V. Ivannikova ${ }^{5}$ \\ ${ }^{1}$ Almaty Technological University, Republic of Kazakhstan, 050012, Almaty, Tole bi Street, 100 \\ ${ }^{2}$ Almaty Technological University, Republic of Kazakhstan, 050012, Almaty, Tole bi Street, 100 \\ ${ }^{3}$ Mendel University in Brno, Republic ofCzech, 61300, Zemědělská 1/1665, \\ ${ }^{4}$ M.Kh.Dulaty Taraz State University, Republic of Kazakhstan, 080000, Taraz, Tole bi Street, 60 \\ ${ }^{5}$ M.Kh.Dulaty Taraz State University, Republic of Kazakhstan, 080000, Taraz, Tole bi Street, 60,
}

\begin{abstract}
The aim of this study is the possibility of using individual lysozyme-containing vegetable juices as a source of inhibition of thermophilic microorganisms that cause rope disease in the production of bread from whole grain wheat flour. Whole grain flour is a rich source of vitamins, enzymes, essential amino acids and minerals (zinc, selenium, magnesium, etc.) [1]., due to the content of a whole grain, however, a large fraction of the outer layer can be seeded with many bacteria that remain in a viable state after baking bread $[2 ; 3]$. The study found that whole grain flour is infected with bacteria belonging to the thermostable family of bacilli. It was revealed that in $1 \mathrm{~g}$ of whole grain flour contains - 80-87 CFU/g of Bacillus cereus. and 9-17 CFU/g of Bacillus mesentericus. Such an indicator is considered slightly infected by the criteria of grain and flour quality according to microbiological indicators (GOST 10444.15-94). Even if the spore bacteria do not cause rope disease or under the condition of weak infection, the presence of these bacteria in the finished product is still undesirable. According to literature sources, lysozyme-containing plants were examined and selected - their individual species (Brássica olerácea, Brassica rapa, Állium satívum, Zīngiber officināle) according to the degree of their inhibition of bacteria [5;6]. It is known that natural antimicrobial compounds can be used as food preservatives to protect foods and extend shelf life [7]. According to the results of suppressing bacteria of the genus Bacillus, cabbage juice (Brássica olerácea) has an inhibitory property, which, in addition to bactericidal activity, is marked by a bacteriostatic effect, that is, it inhibits the growth and reproduction of bacteria. Laboratory baking with the introduction of cabbage juice in different percentages were tested, the sensory characteristics of the finished product were investigated. An optimal dosage of
\end{abstract}

Keywords: Whole grain flour, infection, bacteria of the genus Bacillus, vegetables, inhibition, cabbage juice, lysozymecontaining components.

\section{INTRODUCTION}

The basis of modern ideas about proper nutrition is the developed concept of a balanced diet, which provides for the need to fully meet the needs of the body. An important component of healthy and relatively accessible to all social groups of the population food can be attributed to cereals, vegetables, fruits and berries, as they are the main source of vitamins and dietary fiber [8]. Currently, in the food industry, much attention is paid to the development of new types of flour products with the introduction of whole grain wheat flour. Whole grain flour (WGF) is a flour made from grain that is not peeled from the outer layers of the endosperm, embryo, and shell [9]. Without them, grain is a refined product with a high content of carbohydrates, causing gastrointestinal tract obstruction, obesity, and other diseases $[1 ; 9]$. Since whole-grain flour is not cleaned of the outer layer of the endosperm, the seeds are seeded with microbiological fungi and spore-forming bacteria that have the ability to produce toxic substances by chemical nature [12]. Eating foods contaminated with pathogenic microflora causes human disease. Seediness of grain not only leads to food spoilage, but also reduces the quality of food products, which has an undesirable effect on the quality of the finished product and on human health in general, which is a worldwide safety problem [13].

The problem of microbiological contamination of grain is considered global on a world scale and is in the center of attention of many international organizations, as it is one of the main factors determining the health of the population and the preservation of its gene pool [14].

Various synthetic chemical preservatives are used to control microbial food spoilage and to extend the shelf life of the product. Researchers and consumers do not recommend the use of synthetic preservatives because of their negative effects on human health [20]. Natural antimicrobials have attracted the attention of researchers and food manufacturers due to their safety and non-toxicity [16]. Natural preservatives are easily obtained from plants, animals, and microbes [17]. These natural antimicrobial agents can be isolated from local sources using various advanced methods. 
Spore bacteria entering the human body can cause very serious disturbances in the functioning of the immune system, gastrointestinal tract, liver, respiratory system, and nervous system [18]. Even if spore bacteria do not cause rope disease, their presence in finished products is undesirable, since even a small amount of B. subtilis and B. licheniformis in food products can cause a mild form of foodborne disease [19]. In recent years, the spread of wheat bread disease caused by Bacillus has been observed [20]. This situation is associated with the discovery of a large number of mini-bakeries, where microbiological control of incoming raw materials is not fully carried out. Which is especially true when using bran, which is a source of pathogenic microflora.

Due to the potentially adverse effect of some synthetic fungicides and preservatives on the environment and human health, regulatory authorities require manufacturers to use additives that do not contain synthetic preservatives in food production, preferring natural ones [21]. As an alternative, it is recommended to include natural preservatives derived from plants, and the microorganisms themselves, as well as their active antimicrobial metabolites for food. The use of such natural agents will create consumer confidence in the quality of food products. These alternatives complement barrier technologies. However, the use of natural agents for the preservation of food products is not regulated in many countries, and the intake of some of them raises questions related to the impact on human health, especially when consumed for a certain period of time [22].

Plant types of raw materials used as biological preservatives and possessing antimicrobial properties include turnip, horseradish, papaya, fig, radish, cabbage [6; 7]. There are scientific studies in the field of the use of lysozymecontaining biopolymer complexes of plant origin as preservatives in the food industry and medicine. The Odessa National Academy of Food Technologies has developed a method for isolating lysozyme-containing components in the form of complexes with polysaccharides. Plants of the cabbage family (Brassicaceae) were considered as lysozymecontaining raw materials: horseradish (Armoracia rusticana) and white cabbage (Brassica oleracea). Their functionalphysiological properties and biomedical evaluation of lysozyme-containing biopolymer complexes with Armoracia rusticana and Brassica oleracea were characterized [23].

The aim of this study is the possibility of using individual lysozyme-containing vegetable juices as a source of inhibition of thermophilic microorganisms that cause rope disease in the production of bread from whole grain wheat flour.

\section{MATERIALS AND METHODS}

\subsection{Materials}

For research, wheat grain of "Daulet" variety was used - a variety bred at the "Kazakh Research Institute of Agriculture and Plant Growing". Whole grain flour was obtained by grinding in a CD1 mill (CHOPIN Technologies, France). Bacterial strains isolated from the studied whole grain wheat flour were used as test microorganisms: Bacillus cereus No. 1; Bacillus mesentericus No. 2.

As a lysozyme-containing raw material of plant origin used: ginger (Zīngiber officināle), turnips (Brassica rapa), cabbage
(Brássica olerácea), garlic (Állium satívum). The test samples were squeezed from vegetables in the form of juices. Sample No. 1 - ginger juice, sample No. 2 - turnip juice, sample No. 3 - cabbage juice, sample No. 4 - garlic juice, sample No. 5 radish juice. Previously, juices were filtered using a syringe filter with a pore diameter of $0,22 \mu \mathrm{m}$, to ensure purity and prevent possible pathogenesis.

Microbiological reagents and equipment.

Solutions and culture media: Müller-Hinton agar (MHA), Müller-Hinton broth (MHB), 0,9\% sodium chloride solution (saline).

Equipment: DEN-1 densitometer (Latvia), "Comfort" thermal shaker (Germany), LB 210-A analytical balance (Russia), PB11 pH meter (Germany), SystecV-120 vertical autoclave (Germany), BD-115 thermostat ( Germany), BioIIA/G laminar box (Spain), IKA MS3 Digital shaker (Germany), Eppendorf dispenser (1-10 ml, 100-1000 $\mu \mathrm{l}, 20-200 \mu \mathrm{l}, 0,5-10$ $\mu \mathrm{l})$ (Germany), HaakeP14 thermal bath (Germany), Arium $611 \mathrm{VF}$ water treatment system (Germany).

\section{METHODS}

\subsection{Microbiological control of bread}

The primary identification of isolates, obtaining pure cultures, the study of morphological, cultural, tinctorial and physiological-biochemical properties was carried out according to the method of "The determinant of Bergeybacteria".

The quantitative content of spore bacteria was determined by the Koch method. From each dilution, TSA (tryptone soy agar) was plated on solid nutrient medium. The plated cups were incubated in thermostat at $(37 \pm 1){ }^{\circ} \mathrm{C}$ for 72 hours.

Biochemical, tinctorial and morphological tests were carried out: mobility was determined by stabbing in semi-liquid agar; lecithinase activity - by plating on an VSA (vitelline-salt agar), catalase activity — by adding a culture of a few drops of $3 \%$ hydrogen peroxide on a glass slide, hydrolysis of starch, fermentation of mannitol, salicin and xylose was determined by stabbing in agar with appropriate carbohydrates and phenol red, as an indicator. Hemolytic activity was determined by plating on plates with $5 \%$ blood agar. The Voges-Proskauer reaction was determined on standardized MR-VP medium. The tinctorial properties of the isolates were studied by staining Gram smears using a standard commercial kit and further light microscopy.

\subsection{Determination of antimicrobial activity.}

To prepare inoculum, aliquot daily-cultured test strain was introduced into a sterile tube with $5 \mathrm{ml}$ of $0,9 \% \mathrm{NaCl}$, and then placed in a densitometer DEN-1 to measure the optical density (turbidity) and, accordingly, to achieve the desired concentration of the microorganism. The density of the primary suspension should be 0,5 units according to Mcfarland, which corresponds to $1,5 \times 10^{8} \mathrm{CFU} / \mathrm{ml}$.

Antimicrobial activity was determined by the method of double serial dilutions in a liquid nutrient medium - MuellerHinton broth (standard medium for the study of antibiotic sensitivity), according to the international standard CLSI M100-S25, 2015 "Performance Standards for Antimicrobial Susceptibility Testing" - M100-S25, 2015, - Vol 35 - No 3 and guidelines "Guidelines for determining the sensitivity of 
microorganisms to antibacterial drugs. MUK 4.12.1890-04. Moscow. 2004".

After a series of dilutions, $0,05 \mathrm{ml}$ of test strains of microorganisms at a concentration of $1,5 \times 10^{6} \mathrm{CFU} / \mathrm{ml}$ in triplicate were added to all tubes. Samples were incubated for 18-24 hours at a temperature of $37 \pm 1{ }^{\circ} \mathrm{C}$. After the incubation time, seeding on Petri dishes was performed to determine living cells. After seeding, the plates were placed in a thermostat for $18-24$ hours at a temperature of $37 \pm 1{ }^{\circ} \mathrm{C}$ for bacteria.

The results were taken into account by the presence of visible growth of microorganisms on the surface of a dense nutrient medium. Minimum bactericidal dilution was considered the smallest dilution that suppressed the growth of microorganisms.

\subsection{Bread making technology}

Straight dough method involves the introduction of all raw materials during the dough kneading: the use of whole grain flour, "Almaty" yeast, table salt and drinking water, lysozyme-containing raw juice to suppress Bacillus bacteria, selected on the basis of microbiological analysis. The main and auxiliary raw materials are preliminarily prepared: water is brought to a temperature of $32{ }^{\circ} \mathrm{C}$, yeast is dissolved in it to prepare a yeast suspension. The juice of lysozyme-containing raw material is introduced into water. A saline solution of 0,26 concentrations is prepared and filtered. The dough kneading is carried out in a TEDDY mixer ("Bear Varimixer", Denmark).

Table 1: The list of studied combinations

\begin{tabular}{ll}
\hline Variants & The combination of the studied materials $\%$ \\
\hline T0 & $100 \% \mathrm{WF}$ \\
\hline T1 & $100 \% \mathrm{WF}+5 \% \mathrm{PJ}$ \\
\hline T2 & $100 \% \mathrm{WF}+10 \% \mathrm{PJ}$ \\
\hline T3 & $100 \% \mathrm{WF}+15 \% \mathrm{PJ}$ \\
\hline T4 & $100 \% \mathrm{WF}+20 \% \mathrm{PJ}$ \\
\hline T5 & $100 \% \mathrm{WF}+25 \% \mathrm{PJ}$ \\
\hline WF - whole wheat flour; $\mathrm{PJ}-$ plant juice
\end{tabular}

WF - whole wheat flour; PJ - plant juice

The dough humidity should be about $49 \%$ at an initial temperature of $28-30{ }^{\circ} \mathrm{C}$. Fermentation of the dough is carried out at a temperature of $30-31{ }^{\circ} \mathrm{C}$ for about 150 minutes. The duration of the dough fermentation is 210 minutes. The finished dough is divided into pieces weighing 400 grams. Manually round the dough pieces and place them for proofing in the Sinmag CLT04-09 proofing cabinet at a temperature of $32-35{ }^{\circ} \mathrm{C}$ for 40 minutes at a relative humidity of $85 \%$. Baking bread is carried out in a convection, rotary mini-oven $\mathrm{S} 400$ for $35-40$ minutes with steam humidification of the baking chamber at a temperature of 200$210^{\circ} \mathrm{C}$. Baked bread is cooled and stored at room temperature.

\subsection{Organoleptic evaluation of bread}

The prepared whole wheat bread was allowed to cool for 1 hour at room temperature, and then evaluated. A group of ten judges was created (using the questionnaire) of regular bread consumers, the bread was examined using a 9-point hedonic scale, as recommended by Land and Shepherd (1984) with a scorecard from 1 to 9 , where $1=$ really dislike it, $5=$ satisfies and $9=$ really like it. Product evaluation options: crumb grain, texture, crumb color, aroma and general acceptability. A bulletin was prepared to assess the sensory characteristics of bread with the addition of various options for vegetable juice.

\section{RESULTS AND DISCUSSION}

\subsection{Isolation of microorganisms of the genus Bacillus spp. from the studied flour}

After the incubation time, only in the first dilution of $1 \times 10^{-1}$, microorganisms of the genus Bacillus spp. of two species were detected that were seeded into tryptone soy agar plates for further studies (Figure 1). The number of colony forming units in terms of $1 \mathrm{~g}$ of dry flour was: for the first type of colonies (dry wrinkled colonies of grayish-white color) - 80 $\mathrm{CFU} / \mathrm{g}$, for the second type of colonies (yellowish brown dry wrinkled colonies) - $10 \mathrm{CFU} / \mathrm{g}$.

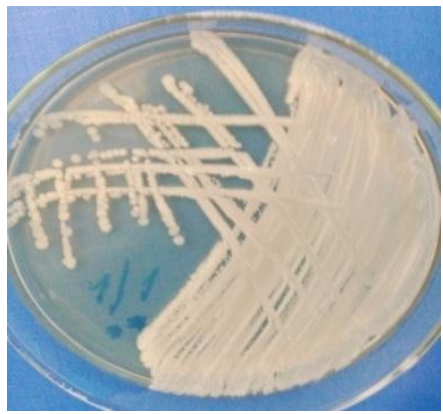

a) Dry wrinkled colonies of grayish-white color

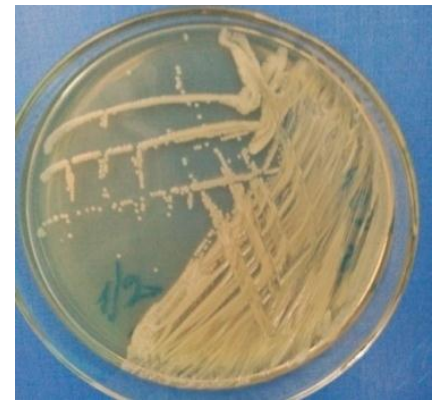

b) Yellowish-brown dry wrinkled colonies
Figure 1: View of Bacilus colonies on TSA medium (tryptone-soy agar)

Under microscopy of smears of the first type of colonies, the cells looked like gram-positive rods with endospores (Figure 2).

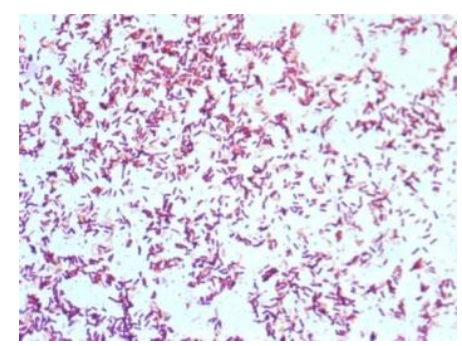

a) Colony No. 1

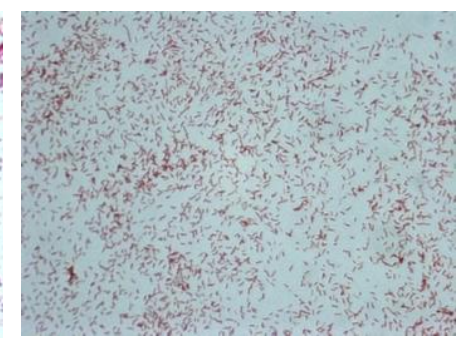

b) Colony No. 2
Figure 2: Micrograph of smears from colonies grown from flour Gram stain. Zoom x100 under immersion.

The cells of the colonies of the second type in the smear have the appearance of thin rods stained gram-positive. Some cells form short strands.

The test results for the lecithinase and hemolytic activity of the selected cultures are presented in Figures 3-4. 


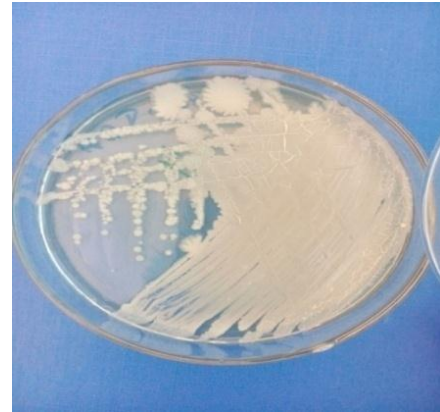

a) Colony No. $1(+)$

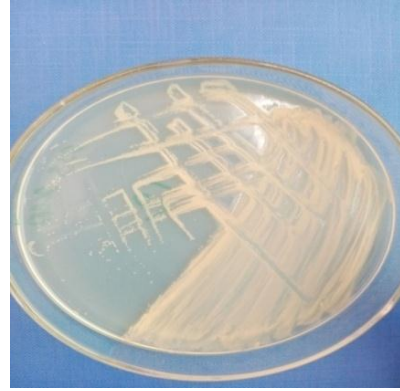

b) Colony No. 2 (-)

Figure 3: The growth of the colonies of the first and second type on a plate with VSA (lecithinase activity test)

Figure 3 shows that the colonies of the first type form small zones of turbidity, which indicates a weak lecithinase activity. Colonies of the second type do not possess lecithinase activity (the absence of turbidity zones around the colonies and the iris on the vitelline-salt medium).

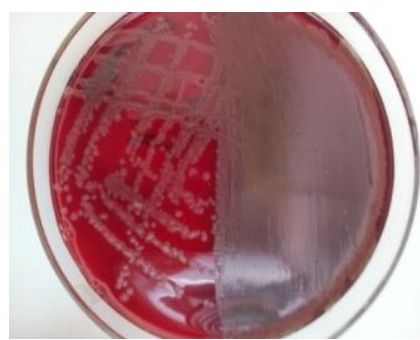

a) Colony No. 1: $\alpha$ - hemolysis

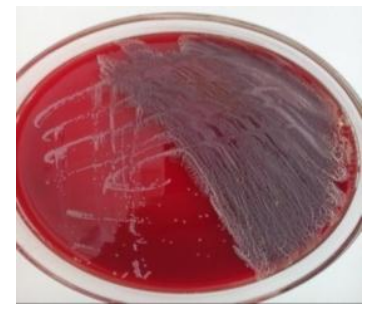

b) Colony No. 2: $\alpha$ hemolysis

Figure 4: The growth of colonies of the first and second type on a plate with blood agar (hemolytic activity test)

Figure 4 ( $a$ and $b$ ) shows that the growth of colonies of both the first and second types on blood agar causes the medium in the growth zone of bacteria to acquire a greenish-brown hue, which indicates the presence of hemolytic activity of type $\alpha$ in these isolates.

The generalized results on morphological, tinctorial and biochemical characteristics are presented in Table 2.

Table 2: Basic biochemical, as well as morphological and tinctorial properties of isolated isolates

\begin{tabular}{|c|c|c|}
\hline Tests & Colony No. 1 & Colony No. 2 \\
\hline $\begin{array}{c}\text { Cell morphology } \\
\text { and tinctoriology }\end{array}$ & $\begin{array}{c}\text { Gram-positive rods } \\
\text { with centrally } \\
\text { positioned endospores }\end{array}$ & $\begin{array}{c}\text { Gram-positive thin } \\
\text { rods forming } \\
\text { endospores }\end{array}$ \\
\hline Colony type & $\begin{array}{c}\text { Dry wrinkled colonies } \\
\text { of grayish-white color }\end{array}$ & $\begin{array}{c}\text { Yellowish-brown } \\
\text { dry wrinkled } \\
\text { colonies }\end{array}$ \\
\hline Mobility & + & + \\
\hline $\begin{array}{c}\text { Lecithinase } \\
\text { activity }\end{array}$ & + & - \\
\hline Catalase activity & + & - \\
\hline $\begin{array}{c}\text { Voges-Proskauer } \\
\text { test }\end{array}$ & + & \\
\hline
\end{tabular}

\begin{tabular}{|c|c|c|}
\hline $\begin{array}{c}\text { Hemolytic } \\
\text { activity }\end{array}$ & $+(\alpha$-hemolysis $)$ & $+(\alpha$-hemolysis $)$ \\
\hline $\begin{array}{c}\text { Hydrolysis of } \\
\text { starch }\end{array}$ & + & - \\
\hline $\begin{array}{c}\text { Hydrolysis of } \\
\text { mannitol }\end{array}$ & - & + \\
\hline $\begin{array}{c}\text { Xylose } \\
\text { fermentation }\end{array}$ & + & + \\
\hline Salicin & + & - \\
\hline
\end{tabular}

Summarizing the results of morphological, cultural, tinctorial and biochemical characters, it can be argued that colony No. 1 is gram-positive rods with endospores located centrally, grow on the medium in the form of dry wrinkled colonies of grayish-white color, are motile, have lecithinase, catalase, hemolytic activity. They have a positive Foges-Proskauer reaction (ferment glucose under anaerobic conditions), hydrolyze starch, ferment xylose and salicin and do not ferment mannitol. These characters are close to those characteristic of the species Bacillus cereus.

Colony No. 2 is characterized by the growth in a dense nutrient medium of dry wrinkled yellowish-brown colonies. In the smear, the cells are represented by gram-positive thin rods with endospores. According to the results of biochemical studies, the cells are motile, catalase-positive, have hemolytic activity, ferment mannitol and xylose. Leticinase activity is absent, have a negative response in the Voges-Proskauer reaction, do not hydrolyze starch, and do not ferment salicin. Based on the studies, it is presumed that isolate of colony No. 2 can be attributed to the species Bacillus mesentericus.

\subsection{Antimicrobial activity of extracts against bacteria of the genus Bacillus}

The results of a study of the antibacterial activity of samples against bacteria of the genus Bacillus are presented in Table 3. From the data presented in Table 3 it is seen that not all test samples exhibit the expected biological activity against test strains.

Table 3: Results of antimicrobial activity of samples obtained by serial dilution

\begin{tabular}{|c|c|c|}
\hline \multirow{2}{*}{ Test sample } & \multicolumn{2}{|c|}{ Test strain } \\
\cline { 2 - 3 } & Bacillus cereus & Bacillus mesentericus \\
\cline { 2 - 3 } & \multicolumn{2}{|c|}{ Minimum bactericidal dilution } \\
\hline Sample No. 1 & NA & NA \\
\hline Sample No. 2 & $1: 1$ & $1: 1$ \\
\hline Sample No. 3 & $1: 2$ & $1: 2-1: 8$ (bacteriostatic effect) \\
\hline Sample No. 4 & NA & NA \\
\hline Sample No. 5 & $1: 2$ & $1: 1$ \\
\hline \multicolumn{2}{|c|}{ NOTE: "NA" - does not have antimicrobial activity. } \\
\hline
\end{tabular}

Analysis of the activity of the extracts showed that in a dilution of $1: 1$, sample No. 2 has bactericidal activity against both test strains. 
Sample No. 3 is effective against Bacillus cereus at a dilution of 1:2, and against Bacillus mesentericus at dilutions from 1:2 to $1: 8$ it had a pronounced bacteriostatic effect.

At a dilution of 1:2, sample No. 5 inhibited the growth of the Bacillus cereus strain, and at a dilution1:1, the growth of the Bacillus mesentericus strain.

Sample No. 1 and sample No. 4 were ineffective relative to these test strains.

Thus, comparing the results, we can conclude that the most effective in the fight against bacteria of the genus Bacillus is sample No. 3, which, in addition to bactericidal activity, has a bacteriostatic effect, that is, it inhibits the growth and reproduction of bacteria. Sample No. 2 and sample No. 5 have a less pronounced bactericidal effect, inhibiting the growth of bacteria of the genus Bacillus only in dilutions of 1:1-1:6.

According to the results of antimicrobial activity, sample No. 3 - cabbage juice - was selected for further research.

\subsection{Organoleptic evaluation of bread with cabbage juice}

The lightness values $L$ of bread with added cabbage juice in various percentages were lower in all samples than in the control bread sample (Table 4). That is, bread with cabbage juice was lighter than the control group. The color values $+\mathrm{a}$ and $+b$ for whole grain bread with added materials changed significantly from 4.62 to 4.75 and from 18.73 to 19.02 , respectively. In general, the color values $+a$ and $+b$ for whole grain bread with added materials were higher than that of the control group.

Table 4: Crumb color

\begin{tabular}{|c|c|c|c|}
\hline \multirow{2}{*}{ Variants } & \multicolumn{3}{|c|}{ Crumb color } \\
\cline { 2 - 4 } & $\mathrm{L}$ & $+\mathrm{a}$ & $+\mathrm{b}$ \\
\hline T0 & $57.12 \pm 0.05^{\mathrm{a}}$ & $4.62 \pm 0.03^{\mathrm{e}}$ & $18.73 \pm 0.12^{\text {defgh }}$ \\
\hline T1 & $57.23 \pm 0.21^{\mathrm{abc}}$ & $4.65 \pm 0.01^{\mathrm{e}}$ & $18.87 \pm 0.05^{\text {defgh }}$ \\
\hline T2 & $57.16 \pm 0.03^{\mathrm{abc}}$ & $4.69 \pm 0.07^{\mathrm{e}}$ & $18.95 \pm 0.04^{\text {defgh }}$ \\
\hline T3 & $57.03 \pm 0.01^{\mathrm{abc}}$ & $4.72 \pm 0.05^{\mathrm{e}}$ & $19.15 \pm 0.13^{\text {defgh }}$ \\
\hline T4 & $56.87 \pm 0.10^{\mathrm{ab}}$ & $4.74 \pm 0.01^{\mathrm{e}}$ & $19.19 \pm 0.07^{\text {defgh }}$ \\
\hline T5 & $56.91 \pm 0.03^{\mathrm{ab}}$ & $4.75 \pm 0.11^{\mathrm{e}}$ & $19.20 \pm 0.01^{\text {defgh }}$ \\
\hline
\end{tabular}

The results of all evaluated sensory attributes are shown in Table 4. No significant differences were observed between sensory characteristics in crumb color, crumb grain, texture, aroma, and general acceptability. The digital values of the crumbcolor index increased with the addition of the studied object - cabbage juice, the indicators changed from 6,00 (T0) to 6,54 (T4) at various ratio percentages. The sensory evaluation of the color index is higher than that of the control sample (T0). In indicators of Crumb grain, the samples had slight differences. Aroma scores were lowest in samples T0 and T5. The highest General Acceptability scores were for T3 in terms of average hedonic scores for all sensory traits tested.
Table 5: The effect of the test material (T) on the sensory characteristics of whole wheat bread (average value \pm SE)

\begin{tabular}{|c|c|c|c|c|c|}
\hline Variants & $\begin{array}{c}\text { Crumb } \\
\text { grain }\end{array}$ & Texture & $\begin{array}{c}\text { Crumb } \\
\text { color }\end{array}$ & Aroma & $\begin{array}{c}\text { General } \\
\text { acceptability }\end{array}$ \\
\hline T0 & $5.45 \pm 0,07$ & $5.20 \pm 0,02$ & $6.00 \pm 0,03$ & $6.15 \pm 0,11$ & $5.00 \pm 0,05$ \\
\hline T1 & $6.86 \pm 0,11$ & $5.07 \pm 0,04$ & $6.35 \pm 0,13$ & $6.85 \pm 0,03$ & $5.86 \pm 0,09$ \\
\hline T2 & $6.33 \pm 0,06$ & $5.45 \pm 0,11$ & $6.51 \pm 0,05$ & $7.45 \pm 0,04$ & $5.13 \pm 0,12$ \\
\hline T3 & $7.46 \pm 0,08$ & $6.87 \pm 0,16$ & $6.45 \pm 0,31$ & $7.99 \pm 0,16$ & $6.97 \pm 0,05$ \\
\hline T4 & $7.24 \pm 0,14$ & $6.75 \pm 0,56$ & $6.54 \pm 0,08$ & $7.92 \pm 0,01$ & $5.23 \pm 0,01$ \\
\hline T5 & $6.12 \pm 0,23$ & $6.26 \pm 0,03$ & $6.53 \pm 0,02$ & $6.12 \pm 0,09$ & $5.11 \pm 0,16$ \\
\hline
\end{tabular}

In general, there were no significant differences in sensory characteristics between the crumbs, crumb color, texture and aroma of whole grain bread (Table 5). However, it has been shown that materials added to whole grain bread samples have a positive effect on all sensory properties. Cabbage juice did not adversely affect product quality and consumer perception. The firmness values of bread with the addition of the studied materials changed from $24.26 \mathrm{~N}$ to $27.08 \mathrm{~N}$ after one day of the storage period (Fig. 1a). Firmness values from whole wheat stored for one day and the control sample had the same values. Based on the studies, it can be assumed that the introduction of cabbage juice in various percentages did not negatively affect the structural and mechanical properties of bread crumb.

a)

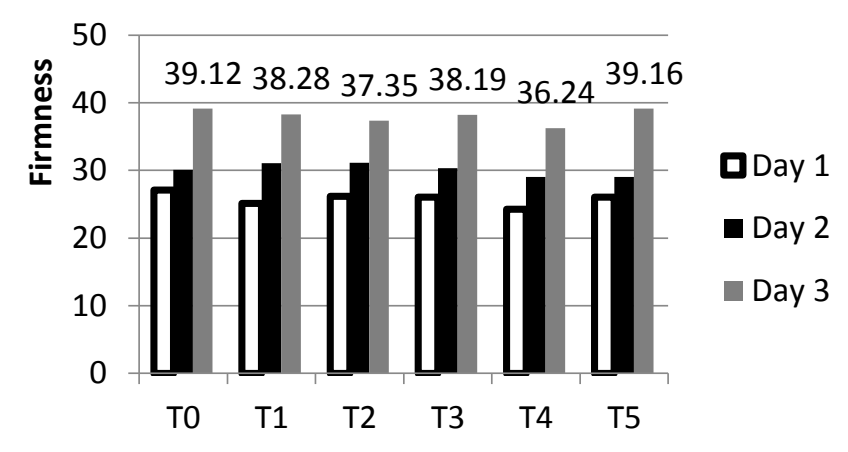

b)

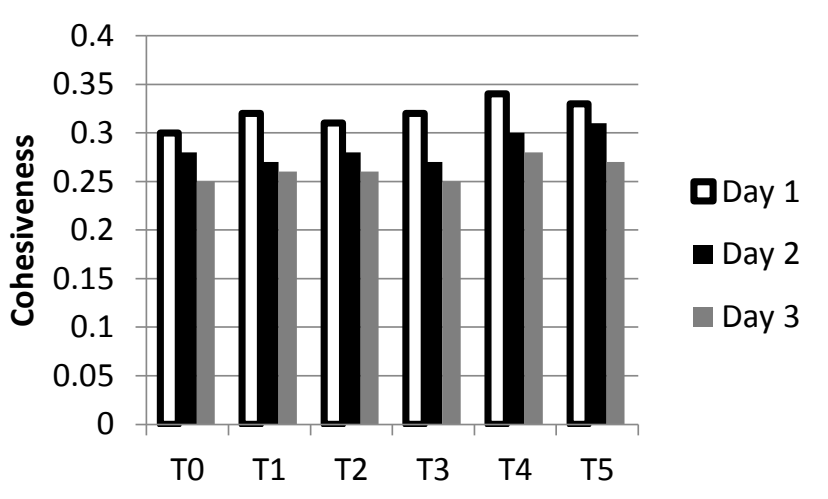

c) 


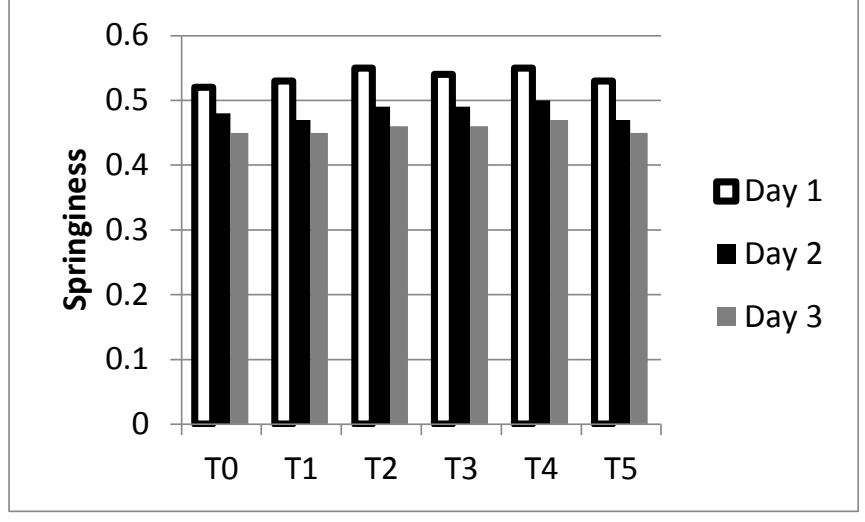

d)

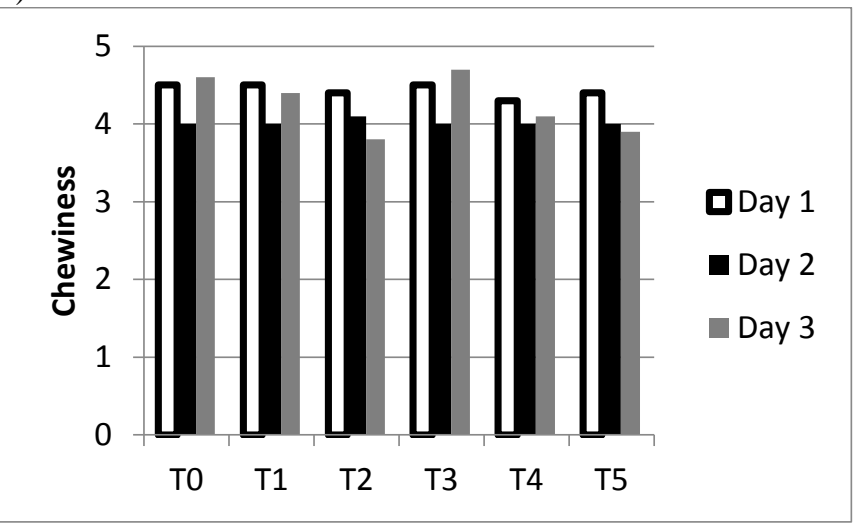

Figure 1: Effect of cabbage juice in\% ratio on (a) firmness values, (b) cohesiveness values, (c) springiness values, and

(d) chewiness values of whole wheat bread

Parallelly, we studied the effect of cabbage juice on the specific volume of bread and the density of the crumb. It is known that the density of the crumb is inversely proportional to the volume of bread, that is, an increase in the density of the crumb is explained by a decrease in the volume of bread [24].

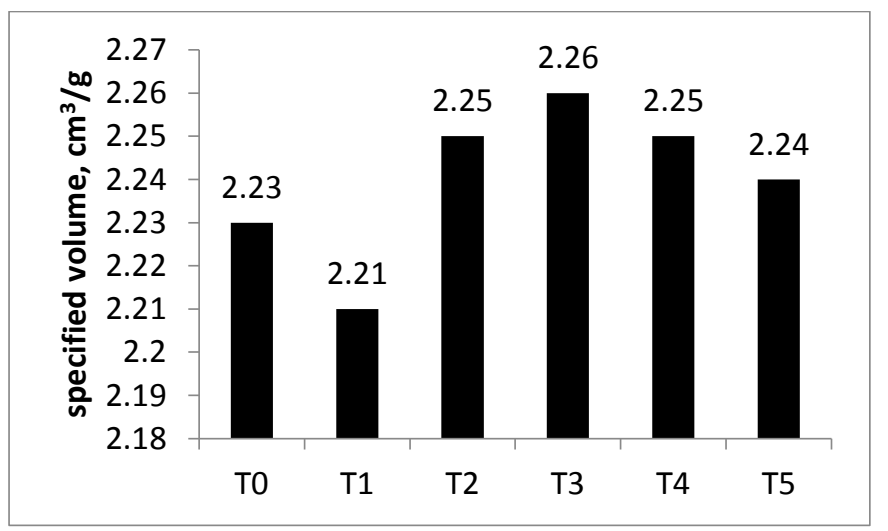

Figure 2: The effect of cabbage juice in $\%$ ratio on the specific volumetric values of whole wheat flour bread.

According to the results of studies, it can be stated that $15 \%$ cabbage juice has a positive effect on both the crumb hardness and the loaf volume. The internal resistance of the bread crumb is evaluated by the cohesion characteristic of chewing. Cohesiveness is defined as how well a product withstands second deformation relative to how it behaved during the first deformation $[25 ; 26]$. In general, cohesiveness in bread samples increases with the addition of test materials (Fig. 1b). The cohesiveness values in all samples containing additional materials were higher than that of the control within 1 day of storage time. The highest cohesiveness values on day 1 were obtained in T5, and it was the lowest in sample T0. Cohesiveness in whole wheat bread samples decreased at different rates with increasing storage time. This reduction in cohesiveness indicates an increased susceptibility of bread to crushing or crumbling.

Springiness is an indicator of how much breadcrumbs bounce after a single squeeze, and can be defined as the elasticity of breadcrumbs; it is also an important parameter for determining the degree of baking of bread [27]. In general, the springiness of bread decreased more significantly, as the shelf life increased from 1 to 3 days. However, when the shelf life increased from 3 to 5 days, the decrease in springiness reached a lesser extent. The quality of the bread was determined by Chewiness. Chewiness is one of the texture parameters that is easily correlated with touch analysis using panels [29]. Chewiness is associated with the work necessary to chew a solid sample, such as bread, until it is swallowed steadily. In general, increasing shelf life reduced Chewiness (Figure 1d). A high Chewiness value was characteristic of sample T3 (WF $+10 \% \mathrm{CJ})$ when stored for 1 day, the lowest is in sample T0.

Despite the advantages of whole grain bread, in view of its useful properties, compared with refined wheat bread, its use is limited for several reasons by consumers: a coarser texture, low volume, due to the lack of gluten [29].

The sensory indicators of bread made from whole grain wheat flour with the addition of cabbage juice in various percentages are presented in Table 4. Statistical analysis showed insignificant differences between the control variant and samples with the addition of cabbage juice, except for the appearance indicator of the bread. The results also showed that bread baked with $15 \%$ cabbage juice was more acceptable than bread with other variants.

\section{DISCUSSION}

Based on the scientific research and processed materials, the following research results should be presented for discussion. 1. In the studied samples, bacteria of the species Bacillus cereus and Bacillus mesentericus were found. The number of colony forming units in terms of $1 \mathrm{~g}$ of dry whole-wheat flour was $80 \mathrm{CFU} / \mathrm{g}$ for a bacterium of the species Bacillus cereus, and $10 \mathrm{CFU} / \mathrm{g}$ for a bacterium of Bacillus mesentericus. The indicated values indicate the safety of the finished product (GOST 10444.15-94). Spore bacteria of the genus Bacillus, entering the human body, can cause very serious dysfunction of the immune system, the gastrointestinal tract, liver, respiratory system, and nervous system. Therefore, even if spore bacteria do not cause rope spoilage of bread, their presence in finished products is undesirable. They may be present in large fractions of the outer layer of whole grain wheat bread. The source of infection may be the air 
environment of the bakery. Statistics show that over the past decade, the number of small and medium-sized enterprises engaged in the production of bread and bakery products using non-traditional raw materials of plant origin, such as bran, seeds, grains and legumes, has increased. Such products are in demand among consumers, however, the feedstock is often a source of Bacillus bacteria, which requires the use of safe preservatives.

2. Lysozyme is found in almost all living things, which is associated with its unique protective function [31]. Lysozyme is a hydrolytic enzyme that selectively breaks down the polysaccharides of the bacterial cell wall. It belongs to smallsized proteins with a molecular weight of about 15 thousand Da.The enzyme is relatively thermostable and can withstand pasteurization temperature [32]. Five types of available lysozyme-containing plants were used: ginger, garlic, turnip, cabbage, radish juice. Juice of turnip, cabbage, radish exhibits biological activity against the genera of Bacillus, in contrast to ginger juice, garlic. Moreover, cabbage juice is more effective and in addition to bactericidal activity has a bacteriostatic effect. The research was to study the effect of cabbage juice with a different percentage on the bacteria of the genus Bacillus.

3. Sensory analysis. Cabbage juice was added in dosages of $5,10,15,20,25 \%$. In the course of sensory analysis, it was found that the optimal dosage of cabbage juice for all organoleptic indicators is T3-15\%. When add juice of cabbage $\mathrm{T} 3-15 \%$ the specific volume was 2,26 .

\section{CONCLUSION}

Whole grain bread can be used as a functional product, accessible to all social layers of the population. However, its component constituents can be carriers of Bacillus bacteria, which produce mainly on the upper layers of the grain. One of the ways to suppress the activity of Bacillus bacteria when making bread from whole grain flour can be considered a method in which cabbage juice is added as a source of lysozyme-containing substances during kneading. The addition of cabbage juice not only significantly improved the quality of the bread, but also reduced the activity of Bacillus bacteria that cause rope diseases. Microbiological studies were the basis for further scientific research in the context of studying the sensory characteristics of bread. Informing the public about the nutritional benefits of functional foods using vegetable juice will expand the assortment line of functional bread and bakery products.

\section{ACKNOWLEDGEMENTS}

We thank the head of the Research Laboratory "Nanoengineering Research Methods" of TarSU, professor, Doctor of Technical Sciences I.I. Bekbasarova, Candidate of Engineering Sciences, professor N.A. Gorbatovskaya for the assistance in conducting research.

\section{REFERENCES}

[1] Johnson, J., \& Wallace, T. C. (Eds.). (2019). Whole Grains and Their Bioactives: Composition and Health.
John Wiley \& Sons.

[2] Spaggiari, M. \& Dall'Asta, C. \& Galaverna, G.. (2019). Food Safety Management of Whole Grains. 10.1201/9781351104760.

[3] Belokurova, E. V., Maslova, V. A., (2017). Prediction and variation of quality indicators of flour culinary products with the introduction of whole grain wheat flour / Quality and safety of products pp. 26-27

[4] https://www.researchgate.net/publication/331993026_I ntroduction_to_Whole_Grains_and_Human_Health 15:46,07.10.2019

[5] Cherno, N.K., Ozolina, S.O., Tiron-Vorobyova, N.B.(2019). Complex processing of plant materials to produce lysozyme-containing biopolymer complexes / Odessa National Academy of Food Technologies, Odessa / http://sdamzavas.net/169962.html/15/84/07b10b2019/sdamzavas.net .

[6] Selivanskaya, I.A. (2013).Lysozyme - a promising component of functional food products / Bread products: technology and food / Grain products and compound feed No. 2 (50) p.12-13

[7] Andryushchenko, S.V., Perunova, N.B., Bukharin O.V.(2015). Molecular mechanisms of the interaction of bacteria with lysozyme and their role in microsymbiocenosis/t. Advances in Modern Biology, Volume 135, No. 5, p. 453-463.

[8] Saranraj, P., Sivasakthivelan, P.(2016). Microorganisms Involved in Spoilage of Bread and Its Control Measures/ 149 (C) by Taylor \& Francis Group, LLC 132- 149 https://www.researchgate.net/publication/328020224_ Microorganisms_involved_in_spoilage_of_bread_and_its_control_measures $\quad 11.10 .2019$ 15-17 hour

[9] Zong, G., Gao, A., Hu, F. B., \& Sun, Q. (2016). Whole grain intake and mortality from all causes, cardiovascular disease, and cancer: a meta-analysis of prospective cohort studies. Circulation, 133(24), 23702380 .

[10] Johnson, J., \& Wallace, T. C. (2019). Introduction to whole grains and human health. Whole Grains and Their Bioactives: Composition and Health, 1-17.

[11] S. Benisi-Kohansa, P.Saneei, M. Salehi-Marzijarani, B. Larijani, A.Esmaillzadeh. Whole-Grain Intake and Mortality from All Causes, Cardiovascular Disease, and Cancer: A Systematic Review and Dose-Response Meta-Analysis of Prospective Cohort Studies1-3 / Advances in Nutrition an intertational review Journal 2016 Nov 15;7(6):1052-1065. doi: 10.3945/an.115.011635. Print 2016 Nov.

[12] Ertl, K., \& Goessler, W. (2018). Grains, whole flour, white flour, and some final goods: an elemental comparison. European Food Research and Technology, 244(11), 2065-2075.

[13] Brunori, Andrea \& Baviello, Gerardo \& Corrado, ZANNETTINO \& Gianluca, CORSINI \& Gergö, SÁNDOR \& Végvári, György. (2010). The use of tartary buckwheat whole flour for bakery products: recent experience in Italy. Annals of the University Dunarea de Jos of Galati. Fascicle VI: Food Technology. 34. 
[14] Feoktistova, N.A., Zolotukhin, S.N., Vasiliev, D.A., Yudina, M.A.(2012). Evaluation of the quality of wheat flour for the presence of pathogens of rope spoilage of bread Agricultural science and education at the present stage of development: experience, problems and ways to solve them. Type: journal article - scientific article Volume: $1320-327$

[15] Xiu-Qin, Li \& Chao, Ji \& Wei, Yong \& Yun, Ling \& Min-Li, Yang \& Xiao-Gang, Chu. (2008). UPLCPDAD Analysis for Simultaneous Determination of Ten Synthetic Preservatives in Foodstuff. Chromatographia. 68. 57-63. 10.1365/s10337-0080645-z.

[16] Marya, A., \& Salwa, K., (2016). Natural Antimicrobial/Antioxidant Agents in Meat and Poultry Products as Well as Fruits and Vegetables: A Review. Critical Reviews in Food Science and Nutrition. 58. 0000. 10.1080/10408398.2016.1194256.

[17] Sharif, Z. I. M., Mustapha, F. A., Jai, J., Yusof, N. M., \& Zaki, N. A. M. (2017). Review on methods for preservation and natural preservatives for extending the food longevity. Chemical Engineering Research Bulletin, 145-153.

[18] Kermanshahi, H., Shakouri, M. D., \& Daneshmand, A. (2018). Effects of non-starch polysaccharides in semipurified diets on performance, serum metabolites, gastrointestinal morphology, and microbial population of male broiler chickens. Livestock Science, 214, 93-97.

[19] Kevin, D., \& Lorenza, C., \& Francesca, F., \& Gwen, F., \& Sara, V-S, \& Joan, V., \& Kieran, T., \& Jeroen, R., (2018). Prebiotic Wheat Bran Fractions Induce Specific Microbiota Changes. Frontiers in Microbiology. 9. 10.3389/fmicb.2018.00031.

[20] Feng, Y., Wang, L., Khan, A., Zhao, R., Wei, S., \& Jing, X. (2019). Fermented wheat bran by xylanaseproducing Bacillus cereus boosts the intestinal microflora of broiler chickens. Poultry science, 99(1), 263-271. Nychas, George-John \& Tassou, Chrysoula. (2014). Preservatives: Traditional Preservatives - Oils and Spices. 10.1016/B978-0-12-384730-0.00258-5.

[21] Rifda, N. (2019). Natural preservation opportunities and challenges in improving food safety. AIP Conference Proceedings. 2094. 020032. 10.1063/1.5097501.

[22] Naufalin, R. (2019, April). Natural preservation opportunities and challenges in improving food safety. In AIP Conference Proceedings (Vol. 2094, No. 1, p. 020032). AIP Publishing LLC..

[23] Ozolina, S.A., Tiron-Vorobyeva, N.B. (2011).Comprehensive processing of plant materials to produce lysozyme-containing biopolymer complexes / Odessa National Academy of Food Technologies / Proceedings, Issue 40, Volume 2, pp.173-177.

[24] Silagadze, M. A., Gachechiladze, S. T., Pruidze, E. G., Khetsuriani, G. S., Khvadagiani, K. B., \& Pkhakadze, G. N. (2017). Development of new-generation dietary bread technologies by using soya processing products. Annals of Agrarian Science, 15(2), 177-180.

[25] Gull, Amir \& Bhat, Jehangeer \& Afzal, Shaiq \& Wani, Raees ul Haq \& Safapuri, Tariq. (2015). Textural and
Sensory Characteristics of Bread Made from Wheat Flour Supplemented with Water Chestnut. American Journal of Food Science and Nutrition Research. 2. 9497.

[26] Yang, B., Liu, H., Yang, J., Gupta, V. K., \& Jiang, Y. (2018). New insights on bioactivities and biosynthesis of flavonoid glycosides. Trends in food science \& technology, 79, 116-124.

[27] Rind A, Miano TF (2018) Effect of Shortening on Sensory Characteristics of Wheat Bread. J Food Process Technol 9: 741. doi: 10.4172/21577110.1000741 p. 1-4.

[28] Esteller M.S., Pitombo R.N.M., Lannes S.C.S. (2005): Effect of freeze-dried gluten addition on texture of ham- burger buns. Journal of Cereal Science, 41: 1921.

[29] Ortolan, F., \& Steel, C. J. (2017). Protein characteristics that affect the quality of vital wheat gluten to be used in baking: A review. Comprehensive Reviews in Food Science and Food Safety, 16, 369381.

[30] Rusen Metin YildirimMuhammet Arici Effect of the fermentation temperature on the degradation of phytic acid inwhole-wheat sourdough bread/ LWT - Food Science and Technology 112 (2019) 1082242 Received 18 January 2019; Received in revised form 28 May 2019; Accepted 29 May 2019*Corresponding author.Email address:ruseny@yildiz.edu.tr(R.M. Yildirim).LWT - Food Science and Technology 112 (2019) 108224Available online 30 May 201900236438/ (C) 2019 Elsevier Ltd. All rights reserved.T

[31] Pavel, A., LevashovDarya, A., MatolyginaOxana, A., DmitrievaEkaterina, D., OvchinnikovaIrina, Yu. AdamovaNataliya, V., KarelinaVladimir, A., NelyubNikolay, L., EremeevAndrey, V., (2019). Levashov Covalently immobilized chemically modified lysozyme as a sorbent forbacterial endotoxins (lipopolysaccharides Journal Pre-proof To appear in:Biotechnology ReportsReceived PII:S2215017X(19)30436-

9DOI:https://doi.org/10.1016/j.btre.2019.e00381Refere nce:BTRE Date:25 September.

[32] Lopes, N. A., Pinilla, C. M.B.,(2019). Adriano Brandelli.Antimicrobial activity of lysozyme-nisin coencapsulated in liposomescoated with polysaccharidesFood Hydrocolloids 93 (2019) 1-92; Accepted 4 February 2019*Corresponding author. Av. Bento Gonçalves 9500, 91501-970, Porto Alegre, Brazil.E-mail address:abrand@ufrgs.br(A. Brandelli).Food Hydrocolloids 93 1-92Available online 04 February 20190268-005X/ @ 2019 Elsevier Ltd. All rights reserved https://doi.org/10.1016/j.foodhyd.2019.02.009 